\title{
DESENVOLVIMENTO DOCENTE NA ÁREA DA SAÚDE: UMA ANÁLISE
}

\author{
THE DEVELOPMENT OF HEALTH PROFESSORS: AN ANALYSIS
}

Nildo Alves Batista 1

Resumo O desenvolvimento docente é uma temática importante em um momento em que a graduação de todos os cursos superiores em saúde passa por transformações curriculares e metodológicas. Neste artigo, analisam-se concepções, propostas e características deste processo. A partir de um diálogo crítico com a literatura, discutemse a docência universitária em saú de como prática social complexa e interdisciplinar e o desenvolvimento docente em saúde, buscando apree nder singularidades, possibilidades e desafios. Neste contexto, a prática do professor é considerada eixo estruturante dos processos formativos.

Palavras-chave saúde; educação; docente; formação docente.
Abstract The development of professors is a highly important subject at a time when undergraduate programs in all higher-education health courses are going through changes in their curricula and methodologies. This article analyses ideas, propositions and characteristics of the process. By dialoguing with the existing literature, we analyze not only teaching for higher-education in health as a complex and interdisciplinary social practice but also the development of health professors, seeking, thus, to learn the peculiarities, potentials and challenges of the processes. This way, the practice of the professor is considered a crucial axis in training health professionals. Key words health; education; professor; professor training. 


\section{Introdução}

A docência tem sido objeto de análises e estudos a partir do movi mento de transfơmação do ensino superior em saúde no Brasil. Inovações educacionais,incluindo integração disciplinar, ap rendizagem baseada em pro blemas, currículo centrado na comunidade e currículo nuclear, têm sido implantadas e avaliadas. Elas atualizam concepções dive rsas e devem ser submetidas a uma reflexão cuidadosa.

Entende-se que as transformações sociais exigem um diálogo com as propostas pedagógicas, sendo necessário que o professor assuma um lugar de mediador no processo de formação do profissional de saúde, estruturando cenários de aprendizagem que sejam significativos e problematizadores da prática profissional (Brew e Boud, 1998; Harden e Cros by, 2000). Os alunos, por sua vez, organizados em pequenos grupos de estudos autodirigidos, tornam-se mais ativos, interativos e co-responsáveis por seu aprendizado.

As práticas de formação docente constituem desafios importantes para o ensino superior em saúde, desenvolvendo-se a despeito de um panorama acadêmico marcado pela valorização da pesquisa e seus desdobramentos em publicações científicas, um panorama em que a aprendizagem da docência é considerada mera conseqüência da experiência.

Em geral, considera-se secundária a complexidade que envolve a docência em saúde, deixando de reconhecer a existência de uma triangulação central entre ensino, aprendizagem e assistência, além de não se discutirem as especificidades dos cenários do processo ensino-ap rendizagem e seus atores professor, aluno, pacientes, profissionais de saúde e comunidade - cada um com suas demandas específicas (Batista e Silva, 2001). Nesse contexto, a reflexão impõe dilemas e abre perspectivas, inspirando a construção de olhares que articulem diferentes saberes e experiências na tentativa de estabelecer referenciais para o desenvolvimento docente.

As articulações aqui configuradas são fruto da trajetória do autor como formador de professores e de suas pesquisas no campo da formação docente unive rsitária em saúde. Foram cenários privilegiados destas refl exões o Programa de Pós-Graduação Ensino em Ciências da Saúde e a disciplina Formação Didático-Pedagógica em Saúde, oferecida a mestrandos e doutorandos da Escola Paulista de Medicina, da Unive rsidade Federal de São Paulo.

O Programa de Pós-Graduação Ensino em Ciências da Saúde, iniciado em 2003, assume o compromisso com a formação de mestres que estejam aptos para o desenvolvimento de pesquisas sobre o ensino superior em ciências da saúde, que reflitam sobre a unive rsidade e a produção científica e que se apropriem de referenciais teórico-metodológicos que fundamentem o exercício da docência no ensino superior em ciências da saúde. 
Por sua vez, a disciplina Formação Didático-Pedagógica em Saúde, com carga horária de 60 horas, visa a contribuir para a formação do pós-graduando em relação à função docente, sendo oferecida em torno de 15 vezes por ano. Para o desenvolvi mento da proposta de trabalho, parte-se do princípio de que o preparo para a função docente não significa apenas a instrume ntação técnica, mas, fundamentalmente, uma reflexão crítica sobre esta prática e a realidade em que se processa. Para tanto, privilegiam-se discussões sobre o significado e sentido da prática docente e seus múltiplos determinantes, processo de planejamento e construção curricular do ensino superior em saúde, aprendizagem e ensino, inovações metodológicas com ênfase nas metodologias ativa s, práticas avaliativase leitura crítica na formação de professores em saúde (Batista, N., 2004).

\section{A docência universitária em saúde: uma prática social complexa e interdisciplinar}

Compreender o trabalho do pro fessor universitário da área da saúde requer cuidadosos estudos e investigações que busquem articular as dimensões institucionais às dimensões pessoais e coletiva s, pois é na inter-relação de várias pers pectivasque se configura um olhar crítico-reflexivo sobre esse trabalho como prática social. A docência em saúde articula teoria e prática, mediando a construção de saberes e orientando atuações de outras duas práticas sociais - a saúde e a educação. O seu exercício constitui uma práxis, no sentido conceituado por Vázquez (1977), ou seja, a dialética teoria e prática na qual os sujeitos constroem significados e propõem intervenções na realidade.

Analisar e pesquisar práticas sociais implica fazer opções, recortes, delimitações do objeto a ser investigado: são movi mentos permanentes de diferenciação e de integração no percurso de produzir conhecimento. Rios (2002, p. 112) afirma que "identificar algo ou alguém, apontar o que ele é, é sempre mencioná-lo numa situação, isto é, existindo em determinadas coord enadas de tempo e espaço". Com esse pressuposto, é necessário ampliar as concepções de docência unive rsitária, articulando-a em seus constituintes de ensino, pesquisa e extensão. Deve-se, também, nomear e discutir os saberes docentes: curriculares, disciplinares, didático-pedagógicos, experimentais, situando o pro fessor como sujeito do conhecimento (Ta rdif, 2002). Situá-lo como tal, entretanto, envolve a construção de novos sentidos para o próprio processo de produção da ciência.

A emergência do conceito de interdisciplinaridade, nos anos 70, vincula-se à aspiração de integração, em resposta à então crescente fragmentação da ciência. Esse conceito ganhou novos contornos a partir das transforma- 
ções no âmbito das epistemologias científicas, redimensionando o papel das disciplinas, bem como do reconhecimento dos diferentes perc u rsos me todológicos possíveis para se produzir saberes sobre os problemas sociais.

Segundo Bochniak (1992), o trabalho interdisciplinar questiona a produção e a socialização do conhecimento científico, uma vez que se interroga a respeito da (im)possibilidade de uma única perspectiva responder à tarefa de desvendamento, explicação e intervenção na realidade. O modelo de ciência que tem como referencial a compartimentalização do conhecimento em disciplinas, fragmentando o saber e estabelecendo dicotomias em torno das relações entre teoria e prática, razão e emoção, pensar e fazer, parece estar sendo abandonado por não atender mais às demandas da sociedade e da própria comunidade científica.

Este abandono implica a construção de um novo sistema de referência que, superando o anterior, amplie as possibilidades humanas de conhecer, interrogar, duvidar, atuar no mundo. Instaura-se, assim, um período de transição em que o velho modelo luta para manter sua força e hegemonia e o novo, ainda não plenamente constituído, enfrenta críticas e resistências agudas.

Furlanetto (2000) afirma que o movimento interdisciplinar não se re stringiu à simples integração dos conteúdos, mas avançou para a intersecção de territórios disciplinare s, ampliando e desdobrando o seu papel. Este movimento evolui em um panorama polissêmico, condicionado pelos diversos contextos culturais e acadêmicos, sendo ainda recente o investimento na clarificação conceitual. Lenoir (1998) reitera que a teoria interdisciplinar encontra-se em construção.

Com perspectiva similar, Fourez (2001) aponta a complexidade de se lidar com a interdisciplinaridade, pois esta se configura em zonas de fronteira entre as disciplinas, criando ilhas de racionalidade que, na ótica do autor, re p resentam reorganização de saberes a partir de situações singulares, considerando o contexto, os sujeitos envolvidos, as interlocuções privilegiadas, os objetivos delineados, os resultados esperados.

Fazenda (2001), ao discutir os pressupostos teórico-metodológicos da pesquisa interdisciplinar, corrobora as leituras de Lenoir e Fourez e de certo modo as amplia, ao situar a condição 'em construção' da interdisciplinaridade não como lacuna ou falta, mas como um 'vir a ser' que constitui o espaço da transformação, do provisório, do ambíguo. Esse espaço 'entre', que não é o lugar do objeto nem o do sujeito, mas o lugar das interações entre sujeito e objeto, parece constituir o cenário por excelência do movimento interdisciplinar de produzir ciência e socializar conhecimentos.

Na diversidade que marca as conceituações e práticas interdisciplinares, é possível identificar pontos em comum: o sentido de relação, a valorização da história dos diferentes sujeitos e disciplinas envolvidos, o movimento de questionamento e dúvida, a busca por caminhos novos na superação de proble- 
mas do cotidiano, a ênfase no trabalho coletivo e na parceria e o respeito pelas diferenças. A interdisciplinaridade constitui, assim, um dos caminhos para que áreas científicas delimitadas e separadas encontrem-se e produzam novas possibilidades.

Tomar a docência unive rsitária em saúde como prática social interdisciplinar favorece a discussão dos pressupostos que têm orientado não somente a reordenação dos serviços de saúde, mas também as políticas desenvolvidas para os profissionais de saúde. Sobre esse aspecto, Feuerwerker afirma:

“Há necessidade de redefinir refe renciais e relações com diferentes segmentos da sociedade no sentido de a universidade construir um novo lugar social, mais relevante e compro metido com a superação das desigualdades. No campo da Saúde, é indispensável que produção de conhecimento, formação profissional e prestação de serviços sejam tomados como indissociáveis de uma nova prática" (Feuerwerker, 2003, p. 25).

Segundo a autora, uma nova postura em relação ao conhecimento na área da saúde passa, necessariamente, pela implantação de novos espaços formativos na universidade que tragam o diálogo educação-saúde-cidadania como eixo central, superando o paradigma do enfoque na doença em favor do enfoque no processo saúde-doença.

No escopo das superações projetadas, impõe-se o ap rofu n da mento das reflexões sobre o pro fessor e sua formação docente no contexto do ensino superior em saúde, enunciando-se uma nova rede: a interdisciplinaridade, os processos formativos e o reconhecimento dos professores como sujeitos.

\section{As concepções sobre a formação do professor universitário em saúde}

Silva (1997), pesquisando a formação docente em saúde, aponta duas dimensões no processo formativo de professores de medicina: a formação como 'processo de reflexão' e como 'tre in a mento didático/exe rcício docente'. A formação como processo de reflexão envolve o ex a me constante das próprias experiências e o diálogo crítico com as teorias pedagógicas, com o reconhecimento de que a postura reflexi vadeve marcar o trabalho docente e, portanto, precisa ser explorada no processo de formação do professor, uma vez que favorece a construção da autonomia para identificar e superar dificuldades do cotidiano.

O professor orienta suas ações por teorias, explícitas ou não, as quais traduzem seus modos de conceber os alunos, as funções da unive rsidade, o lugar da ciência, as produções científicas. A formação como processo reflexivo supõe a ap reensão dessas teorias e sua discussão, habilitando os pro- 
fessores a pensar, criticar e propor outros itinerários para as relações com o aluno e o conhecimento (Zeichner, 1993).

No entanto, Sadalla et al. (2000) e Pimenta e Anastasiou (2002) alertam para os riscos de se tomar a expressão 'reflexivo' como mais um adjetivo da formação de professores, caindo-se no reducionismo de atribuir-lhes toda a responsabilidade pela mudança na formação superior em saúde, desconsiderando os condicionantes sócio-político-institucionais. As possibilidades de inovação e ruptura que a refl exão pode anunciar parecem ter maior eco em propostas de formação que privilegiem a perspectiva de desenvolvimento docente e o cenário institucional como um espaço de formação permanente (Misukami et al., 2002).

A abord agem da dimensãoreflexiva na formação do pro fessor também encontra ressonância na literatura internacional. Newland et al. (2003), Chism, Lees e Evenbeck (2002) e Musal et al. (2002) sinalizam o quanto as estratégias de desenvolvimento docente que valorizam as experiências dos professores, abordando-as de uma maneira problematizadora e estruturando espaços para a discussão coletiva, têm sido realizadas com envolvimento e comprometimento, gerando maiores possibilidades de mudanças nas práticas pedagógicas.

Chism, Lees e Evenbeck (2002), particularmente, discutem também que o desenvolvi mento de práticas reflexivas, ancoradas no cotidiano docente e cientes dos contextos institucionais, permite pensar a 'formação como processo', o que significa, entre outros aspectos, enfocar a ap rendizagem (situar o professor como sujeito da aprendizagem). Os autores assumem, assim, que "ensinar é uma atividade complexa que requer contínua reflexão e propostas de inovação, refinamento" (p. 39).

A dimensão da formação como 'treinamento/exercício docente' fundamenta-se no arg u mento de que o trabalho do pro fessor exige, necessariamente, um conhecimento sistematizado acerca do processo de planejamento, das estratégias de ensino, das práticas avaliativas e das novas metodologias de informação e comunicação (Sleight et al., 2003; Stone, 2003). Entretanto, os momentos de treinamento apenas se tornam experiências fundamentais na formação docente se ocorrem com envolvimento dos alunos, por meio de uma interlocução que organize e sistematize o que foi vivenciado,discutindo suas implicações para o trabalho do professor.

Bueno, Catani e Sousa (2002) e Misukami et al. (2002), ao descreverem e teorizarem sobre processos de formação vividos em dife rentes pesquisas, apontam a possibilidade de se articular a refl exãocom os dilemas e desafios que se ex pressam no cotidiano docente. Mesmo que as autoras não tenham abordado a docência universitária, seus apontamentos auxiliam na compreensão de que é equivocada a dicotomia pensar-fazer. Segundo Borges e Tardif (2001), o novo referencial para a formação docente reconhece o professor co- 
mo um profissional produtor de saber e de saber-fazer, emergindo daí a necessidade de investigar os sab e res mobilizados e produzidos pelo professor na sua ação cotidiana. As colocações desses autores fornecem os pressupostos para a construção de propostas formativas que busquem trabalhar a integralidade da ação docente.

Pedagogia e didática, que historicamente têm apresentado os conhecimentos sistematizados vinculados ao exercício docente, são compreendidas de dife rentes maneiras. A pedagogia vem sendo entendida como 'fundamento': 1) conectado aos aspectos históricos e sociais, neste caso os relativos à área da saúde; 2) relacionado ao contexto institucional e acadêmico; 3) articulado aos condicionantes filosóficos e epistemológicos da prática docente; e 4) referente ao processo ensino-apren dizagem e à organização do trabalho docente em saúde. Concebê-la como tal agre ga à pedagogia a dimensão do pensamento, da tomada de posição frente às propostas educativa s, da construção de uma apropriação crítica da prática. O caráter pedagógico da atividade docente re fe re-se à constante elaboração de sab eres a partir da prática e da reflexão sobre ela, de modo a situar o docente como autor, em oposição ao professor que aplica técnicas ou desenvolve um plano de ensino prescrito.

Por sua vez, a didática vem sendo entendida como campo do aparato instrumental (técnicas, planejamento e avaliação) que o professor precisa dominar para realizar seu trabalho educativo. Trata-se dos saberes para ensinar já consolidados, que passam por processos próprios da profissão docente, agregando e sistematizando experiências historicamente realizadas em difere ntes opções metodológicas.Nocaso específico da área da saúde, estes saberes estão distantes da prática profissional, de modo que se faz necessária uma formação cuidadosa.

Percebe-se, entretanto,que há uma tendência a reduzir a didática a aspectos tecnicistas, empobrecendo as possibilidades de transformação e ava nço no processo ensino-aprendizagem. O suposto compromisso da didática com um 'modo de ensinar' dissociado das implicações sociais, políticas e educacionais é um reducionismo produzido pela compreensão de prática dentro da ótica empirista e pragmática (Batista, N. e Batista, S., 2002; Pimenta e Anastasiou, 2002).

Ap roximar-se dessas concepções e entendê-las como expressões das marcas históricas que presidem a docência, percebendo os espaços de re ssignificação existentes nas práticas singulares de cada professor, nas interações com os alunos, com os pares e com o conhecimento, abre horizontes para construir espaços de formação que contemplem, discutam e transformem os processos de aprender e ensinar em saúde.

Nas experiências de formação e desenvolvimento docente em saúde, duas pers pectivas têm sido identificadas: a primeira centra o processo no professor-formador, enfatizando os conteúdos científicos, a objetividade e a 
clareza na transmissão das informações e desdobrando-se numa prática baseada em modelos preestabelecidos; já a segunda privilegia o diálogo entre professor-formador e professor-aluno, centrando-se na açãomediadora que articula os saberes do formador aos do aluno (Batista, N. et al., 2000; Foresti e Pereira, 2004; Newland et al., 2003; Orlander et al., 2000).

A perspectivadialógica valoriza as relações entre professor-formador e professor-aluno, os saberes construídos por eles, a prática como objeto de estudos e a análise destes sob a luz de teorias educacionais. O professor-formador situa-se como mediador nos encontros e experiências formativa s, investindo em interações que privilegiam a troca de idéias, as vivências, a discussão coletiva sobre as práticas, o saber já acumulado pelo grupo e os movimentos de teorização das ações docentes (Zabalza, 2004).

Freire (1996) afirma que a prática educativa deve estar revestida de um saber- fazer e de um saber-ser exercitados, em que "a reflexão crítica sobre a prática se torna uma exigência da relação teoria e prática, sem a qual a teoria pode ir virando blábláblá e a prática, ativismo" (p. 24). Defende que, no desenvolvimento docente, “o momento fundamental é o da reflexão crítica sobre a prática. É pensando criticamente sobre a prática de hoje ou de ontem que se pode melhorar a próxima prática" (p. 43). Segundo Monteiro (2001, p. 130), é na busca da construção de um conhecimento prático e na refl exão crítica sobre as práticas que "a categoria do saber docente busca dar conta da complexidade e especificidade do saber constituído no (e para o) exercício da atividade docente e da profissão".

Tomar a própria prática docente, em um movimento de ação-reflexãoação, como um dos pontos de partida para empreender mudanças no cotidiano do ensinar e ap render compreende a articulação teoria e prática, na medida em que o trabalho acadêmico do professor precisa ser confrontado com as teorias existentes. Constituem espaços de aprendizagem por meio do diálogo crítico com a literatura: explicitar o que se faz, conhecer e discutir sobre teóricos que ab ordam conteúdos relativos ao processo ensino-ap re ndizagem, estabelecer vínculos entre os dados de pesquisa e asexperiências — isto parece configurar a formação docente em saúde como um processo em construção.

\section{Formação docente em saúde: singularidades, possibilidades e desafios}

Os contextos em que se desenvolvem as propostas de formação didático-pedagógica na área da saúde contêm singularidades que devem ser compreendidas e discutidas: o domínio do conteúdo e o sucesso da prática profissional são, comumente, considerados suficientes para o exercício da docência; a valorização da formação docente no contexto da pós-graduação brasileira é 
posta em segundo plano em relação à formação do pesquisador; há uma certa desarticulação entre as áreas da saúde e da educação na sociedade em geral e, particularmente, no espaço acadêmico, alimentando uma disputa em torno da responsabilidade de formar o pro fessor; falta uma troca mais sistemática de experiências entre as universidades que desenvolvem práticas de formação docente na área da saúde, pois, atualmente, ficam isoladas as inovações e desconhecidos os avanços conquistados.

A ambigüidade da profissão professor, analisada, entre outros, por Garcia (1999) e Tardif (2002), também se expressa nos cursos superiores em saúde, agravando-se nestes pelo fato de que primeiro se é médico, dentista, fisioterapeuta e somente depois se é professor de qualquer destas áreas. Essa relação acaba fortalecendo um certo mito em torno da 'história natural da docência em saúde', na qual a 'boa prática profissional específica garante a boa docência', sendo recentes os movimentos por uma formação contínua, sistemática e assumida como processo que exige desejo e vontade individual, mas igualmente intencionalidade institucional de propiciar espaços de formação.

Observa-se que na unive rsidade brasileira interagem dife rentes modelos de docência: o pesquisador com total dedicação à universidade e uma sólida formação científica, o professor re p rodutor do conhecimento e o professor que se dedica à atividade acadêmica, mas carece de uma formação consistente para a produção e socialização do conhecimento. A institucionalização de práticas de formação docente, sobretudo no âmbito da pós-graduação $s$ t ricto sensu, torna-se, assim, fundamental, ampliando os movimentos de comprometimento docente já existentes em algumas universidades.

No âmbito das possibilidades, as propostas de desenvolvimento docente em saúde implementadas no cenário nacional parecem concorrer para convergências importantes, realçando o lugar da reflexão sobre a prática. Masetto e Antoniazzi (2004), ao descre verem a experiência que realizaram com professores de odontologia, destacam a importância de que o gr upo de professores seja valorizado em suas experiências didático-pedagógicas e que dialogue e analise essas experiências a partir dos princípios teóricos da aprendizagem, da interação professor-aluno e da tecnologia educacional.

Apresentando criticamente um trabalho junto a pós-graduandos de pediatria, Zeferino e Barros Filho (2004) afirmam que a refl exão e a troca de experiências devem se constituir em objetivos centrais da formação docente compro metida com a aprendizagem significativa tanto de quem ensina como de quem aprende.

Basile (2004), em seus trabalhos com pós-graduandos da área da saúde, enfatiza a necessidade de as práticas docentes serem compartilhadas em um clima de criatividade e compromisso com o estudo de temas relevantes no processo ensino-aprendizagem, assumindo-se uma postura crítica e propositiva frente ao contexto histórico, institucional e cultural. 
A prática situa-se como núcleo das vivências desenvolvidas por Foresti e Pe reira (2004), que afirmam a necessidade de que a formação docente em saúde propicie espaços de mobilização para o conhecimento, de construção e de elaboração de sínteses provisórias desse conhecimento.

Batista, S. et al. (2004), ao analisarem artigos internacionais publicados em periódicos vinculados ao ensino médico, apontam que há um foco importante em propostas dialógicas, reflexivas e que desencadeiam a elaboração de projetos, os quais são desenvolvidos com acompanhamento de professores mais experientes.

Assumir a prática como eixo estruturante do desenvolvimento docente, dimensão que se articula com as experiências do autor, não significa defender uma perspectiva empirista do conhecimento, como se este decorresse linearmente da experiência. Antes, representa compreender o conhecimento como processo de construção, contextualizado em tempos e espaços determinados. De acordo com Fre ire (1996), a realidade instaura questões, e tomá-las como objeto de aprendizagem, empreendendo itinerários de teorização e retorno ao real, transformando-o e sendo transformado por ele, configura movimentos de formação potencialmente significativos.

Desenvolver e avaliar propostas de desenvolvimento docente na área da saúde que privilegiem a prática docente e estruturem momentos de comparação, explicação, interpretação e teorização - assumindo o desenvolvimento docente como um processo continuado, institucional, contemplando a pesquisa em colaboração em uma perspectivainterdisciplinar - é um desafio a ser enfrentado num momento em que o ensino superior busca caminhos éticos, humanistas, competentes e socialmente comprometidos.

\section{Notas}

1 Pro fessor Adjunto e diretor do Centro de Desenvolvimento do Ensino Superior em Saúde (Cedess) da Universidade Federal de São Paulo (Unifesp). Livre-docente em Educação Médica pela Unifesp.<nbatista@cedess.epm.br> 


\section{Referências}

BASILE, Maria Apa recida. 2004. Preparação p e d agógica na USP: experiência desenvolvida na medicina/fisiopatologia experimental. In: BATISTA, Nildo A.; BATISTA, Sylvia Helena S. da S. (orgs.). Docência em saúde: temas e experiências. São Paulo: Senac, p. 234-242.

BATISTA, Nildo A. et al. 2000. Novas demandas, novos desafios na área médica: avaliação de uma estratégia de formação docente. Relatório final de pesquisa. São Paulo, Fapesp. (Mimeo).

. 2004. A disciplina Formação DidáticoPedagógica em Saúde na pós-graduação s tricto sensu da Unifesp/EPM: uma proposta em foco. In: BATISTA, Nildo A.; BATISTA, Sylvia Helena S. da S. (orgs.). Docência em saúde: temas e experiências. São Paulo: Senac, p. 203-212.

; BATISTA, Sylvia Helena S. da S. 2002. Formação do professor universitário: desafios e possibilidades. In: SEVERINO, Antonio J.; FAZENDA, Ivani A. (orgs.). Formação docente: rupturas e possibilidades. Campinas: Papirus, p. 185-205.

_; SILVA, Sylvia Helena S. da S. 2001. O professor de medicina. São Paulo: Loyola.

BATISTA, Sylvia Helena S. da S. da et al. 2004. Desenvolvimento docente em medicina: discutindo tendências a partir da literatura internacional. In: XVII Congresso Brasileiro de Educação Médica, Vitória. Anais. Vitória: Associação Brasileira de Educação Médica (Abem). 1 CD-ROM.

BOCHNIAK, Regina. 1992. Questionar o conhecimento. São Paulo: Loyola.

BORGES, Cecilia; TARDIF, Maurice. 2001. Apresentação. Educação \& Sociedade, v. 22, n. 74, p. 11-26.

BREW, Angela; BOUD, David. 1998. Preparing for new academic role: an holistic approach to development. International Journal of Academic Development, v. 1, n. 2, p. 17-25.

BUENO, Belmira O.; CATANI, Denise B.; SOUSA, Cynthia P. 2002. A vida e ofício dos professores. São Paulo: Escrituras.

CHISM, Nancy V. N.; LEES, Douglas; EVENBECK, Scott. 2002. Faculty deve- lop ment for teaching. Liberal Education, v. 88, n. 3, p. 34-41.

FAZENDA, Ivani. 2001.Interdisciplinaridade: um dicionário em construção. São Paulo: Cortez.

FEUERWERKER, Laura. 2003. Educação dos profissionais de saúde hoje: problemas, desafios, perspectivas, e as propostas do Ministério da Saúde. Revista da Abeno, v. 3, n. 1, p. 24-27.

FORESTI, Mirian C. P. P.; PEREIRA, Maria Lucia T. 2004. Qualidade da docência universitária e formação docente em programas de pós-graduação em saúde: a experiência da Unesp, campus de Botucatu. In: BATISTA, Nildo A.; BATISTA, Sylvia Helena S. da S. (org s.). Docência em saúde: temas e experiências. São Paulo: Senac, p. 243-256.

FOUREZ, George. 2001. Fondements épistémologiques pour l'interdisciplinarité. In: LENOIR, Y ves B.; FAZENDA, Ivani (orgs.). Les fondements de l'interdisciplinarité dans la formation à l'enseignement. Sherbro o ke: Éditions du CRP. do Trabalho, p. 10-12.

FREIRE, Paulo. 1996. Pedagogia da autonomia: sab e res necessários à prática educativa. São Paulo: Paz e Terra.

FURLANETTO, Ecleide. 2000. Formação de professores: desvelando os símbolos para pesquisar interdisciplinarmente. In: ROLDÃO, Maria C.; MARQUES, Ramiro (org s.). Inovação, currículo e formação. Porto: Porto, p. 151-164.

GARCIA, Carlos M. 1999. Formação de professores para uma mudança educativa. Porto: Porto.

HARDEN, Ronald M.; CROSBY, Joy. 2000. The good teacher is more than a lecturer: the twe l ve roles of the teacher. $\mathrm{Me}$ dical Teacher, v. 22, n. 4, p. 334-347.

LENOIR, Yves. 1998. De l'interdisciplinarité scolaire à l'interdisciplinarité dans la formation à l'enseignement: un état de la question. Revue Francaise de Pédagogie, n. 124, p. 121-154.

MASETTO, Marcos T.; ANTONIAZZI, João Humberto. 2004. Odontologia e docên- 
cia unive rsitária: formação pedagógica do docente do curso de odontologia. In: BATISTA, Nildo A.; BATISTA, Sylvia Helena S. da (org s.). Docência em saúde: temas eexperiências. São Paulo: Senac, p. 213-223.

MISUKAMI, Maria das Graças et al. 2002. Escola e aprendizagem da docência: processos de investigação e formação. São Carlos: EdUfscar/Inep.

MONTEIRO, Ana Maria F. C. 2001. Profe ssores: entre sab e res e práticas. Educação \& Sociedade, v. 22, n. 74, p. 121-142.

MUSAL, Berna et al. 2002. Faculty develop ment program in Dokuz Eylül School of Medicine: in the process of curriculum change from traditional to PBL. Medical Education Online, v. 7, n. 2. Disponível em: <www.med-ed-online.org/pdf/ res00030.pdf>. Acesso em: 10 ago. 2004.

NEWLAND, Myrna C. et al. 2003. Experience with a program of faculty development. Medical Teacher, v. 25, n. 2, p. 207-209.

ORLANDER, Fay D. et al. 2000. Co-teaching: a faculty development strategy. Medical Education, v. 34, p. 257-265.

PIMENTA, Selma G.; ANASTASIOU, Lea. 2002. A docência no ensino superio $r$. São Paulo: Cortez.

RIOS, Te rezinha. 2002. Ofício de professor: títulos e rótulos ou a desafiadora construção da identidade. In: ALMEIDA, Ana Maria B.; LIMA, Maria Socorro; SILVA, Silvina P. (orgs.). Dialogando com a escola. Fortaleza: Edições Demócrito Rocha/Uece, p. 110-121.

SADALLA, Ana Maria F. A. et al. 2000. Teorias implícitas na ação docente: contribuição teórica ao desenvolvimento do professor prático-reflexivo. In: AZZI, Roberta G.; BATISTA, Sylvia Helena S. da S ; SADALLA, Ana Maria F. A. (orgs.).
Formação de professores: discutindo o ensino da psicologia. Campinas: Alínea, p. 21-38.

SILVA, Sylvia Helena S. 1997. Professor de medicina: diálogos sobre sua formação docente. Tese de Doutorado, São Paulo: P rograma de Estudos Pós-Graduados em Psicologa da Educação, Pontifícia Universidade Católica de São Paulo.

SLEIGHT, Deborah et al. 2003. Creating online lessons: a faculty development seminar series. Medical Education Online, v. 8, n. 7, p. 1-7. Disponível em: < w w w. med-ed-online.org/pdf/f0000061.pdf $>$. Acesso em: 15 ago. 2004.

STONE, Sarah et al. 2003. Development and implementation of an objective structured teaching exercise (Oste) toevaluate improve ment in feedback skills following a faculty development workshop. Teaching and Learning in Medicine, v. 15, n. 1, p. 7-13.

TARDIF, Maurice. 2002. Saberes docentes e formação profissional. Petrópolis: Vozes.

VÁZQUEZ, Adolfo. 1977. Filosofia da práxis. Rio de Janeiro: Paz e Terra.

ZABALZA, Miguel A. 2004. O ensino universitário: seus cenários e protagonistas. Porto Alegre: Artmed.

ZEFERINO, Angélica M. B.; BARROS FILHO, Antônio A. 2004. Capacitação docente: experiência da pós-graduação em saúde da criança e do adolescente com a disciplina Pedagogia Médica e Didática Especial na FCM/Unicamp. In: BATISTA, Nildo A.; BATISTA, Sylvia Helena S. da S. (orgs.). Docência em saúde: temas e experiências. São Paulo: Senac, p. 225-231.

ZEICHNER, Kenneth M. 1993. A formação reflexiva de professores: idéias e práticas. Lisboa: Educa.

Recebido em 11/03/2005

Aprovado em 03/06/2005 